\title{
Erratum
}

\section{A Synaptic Modification Algorithm in Consideration of the Generation of Rhythmic Oscillation in a Ring Neural Network}

\author{
Kazuyoshi Tsutsumi ${ }^{1}$ and Haruya Matsumoto ${ }^{2}$ \\ 1 Division of System Science, the Graduate School of Science and Technology, Kobe University, Rokkodai, Kobe 657, Japan \\ 2 Department of Instrumentation Engineering, Faculty of Engineering, Kobe University, Rokkodai, Kobe 657, Japan
}

Biol. Cybern. 50, 419-430 (1984)

\subsection{The Number of Cells}

The characteristics of rhythmic oscillation are also affected by the number of cells. Figures 7 and 8 illustrate the relationships between the number of cells $N(N$ : odd number $)$ and the parameters on 4 pairs of $\tau_{1}$, $\tau_{2}, \beta_{1}$, and $\beta_{2}$. As shown in Fig. $7, p$ and $p^{+}$increase linearly in proportion to the number of cells, except in the case of $N=3$, (so that the extended lines may pass through the point of origin), and therefore $p^{+} / p$ is almost constant. When $N \geqq 5$, the influence of the
Fig. 10. The result for the synaptic modification of applying the algorithm proposed in Sect. 5 to the network on the right in Fig. 9. The constants in the algorithm are $\delta^{(1)}=0.0004 / u^{2}, \theta^{(1)}=0.4 u$, $\eta^{(1)}=-2.0 u, \delta^{(2)}=0.0012 / u^{2}, \theta^{(2)}=0.4 u$, and $\eta^{(2)}=0.0 u$. Each figure from the left corresponds to the outputs of excitatory cells at a set of synaptic strengths (see Appendix 2) after 0,180 , or 3000 modification steps

\section{Synaptic Modification}

The synaptic modification algorithm proposed in Sect. 5 is applied to the disturbed ring networks where the rhythmic oscillation has been previously extinguished.

Figure 10 shows the result of the application of the modification algorithm whose constants are $\delta^{(1)}$ $=0.0004 / u^{2}, \theta^{(1)}=0.4 u, \eta^{(1)}=-2.0 u, \delta^{(2)}=0.0012 / u^{2}$,

Verantwortlich für den Textteil: Prof. Dr. W. Reichardt, Max-Planck-Institut für biologische Kybernetik, Spemannstr. 38. D-7400 Tübingen. Verantwortlich für den Anzeigenteil: E. Lückermann, G. Sternberg, Springer-Verlag, Kurfürstendamm 237, D-1000 Berlin 15. Fernsprecher: (030)8 821031. Telex: 01-85411. Springer-Verlag, Berlin - Heidelberg. New York. Tokyo. Druck der Brühischen Universitätsdruckerei, Gießen. Printed in Germany. - C Springer-Verlag Berlin Heidelberg 1984 